\title{
Comparative Study on Antioxidant Activity and Multi-drug Resistance Reversing Activity in Korean Colored Soybean Cultivars
}

\author{
Hee-Ock Boo, Jong-Ill Lee ${ }^{1}$, Kaihei Koshio ${ }^{2}$, Won-Seob Song ${ }^{3}$ and Sang-Uk Chon ${ }^{4}$ * \\ Department of Biology, Chosun University, Gwangju 501-759, Korea \\ ${ }^{1}$ Department of Oriental Medicine Resources, Sunchon National University, Sunchon 540-742, Korea \\ ${ }^{2}$ Department of International Agricultural Development, Tokyo University of Agriculture, Tokyo 156-8502, Japan \\ ${ }^{3}$ Department of Horticulture, Sunchon National University, Sunchon 540-742, Korea \\ ${ }^{4}$ EFARINET Co. Ltd., BI Center, Chosun University, Gwangju 501-759, Korea
}

\begin{abstract}
The purpose of this study is to analyze antioxidant activity and multidrug resistance reversing activity in several Korean colored soybean (Glycine max Merr.) cultivars. Antioxidant activity of methanol extracts from colored soybean cultivars was evaluated by TBARS (thiobarbituric acid reactive substances), DPPH (1, 1-diphenyl-2-picrylhydrazyl) and ABTS (2,2'-azino-bis (3-ethylbenzothiazoline-6-sulphonic acid) methods. By means of TBARS, cultivar "Jeonnam \# 1" showed the highest activity until 7 days, and followed by "Black \# 1", "Jinyul" and "Black \# 3", showing lower activity than that of BHT (butylated hydroxytoluene). Methanol extracts of all cultivars proved that DPPH radical scavenging activity is dose-dependent. Methanol extract from cultivar "Jeonnam \# 1" showed highest DPPH radical scavenging activity, and followed by cultivars "Black \# 1". MDR (multi-drug resistance reversing) activity, however, showed the highest effect in "Black \# 3" and the lowest "Black \# 1" cultivar. These results suggest that seed colors of soybean may play an important role in antioxidant activity and MDR activity.
\end{abstract}

Key words - Anthocyanin, Antioxidant activity, Multi-drug resistance (MDR), Colored soybean

\section{Introduction}

Soybean is the most important legume and the major source of protein in the Oriental diet. It also is a rich source of isoflavonoids and other phenolic metabolites which have antioxidant activity. Although many researches have shown the chemopreventive properties of purified and synthetic isoflavonoids (Darbon et al., 2000; Wei et al., 1995), recent research has shown that fermented soy performed better at reducing incidence of mammary tumor risk than a similar mixture of its constituent isoflavonoids (Ohta et al., 2000), suggesting that the food background may play a positive role in the chemopreventive actions of its resident isoflavonoids. Notably, fermented soybean is rich in phenolic aglycones which are more active and more readily taken up than their $\beta$-glycosides (Esaki et al., 1997). A variety of health-related functions of soybeans have now been identified, including the ability to inhibit lipid peroxide reactions and radical generation

${ }^{*}$ Corresponding author. E-mail : chonsu4100@yahoo.co.kr which cause aging and cancer. More formally, soybean has antioxidant and radical scavenging activities (Tsuda et al., 1999). Such functions could be especially strong in colored cultivars which contain an anthocyanin or $\beta$-carotene giving it black, red or yellow soybean. Recently, antioxidants have attracted special attention because they can protect human body from oxidative stress which may cause many diseases including cancer and aging (Kim et al., 2008; Miers et al., 2001; Tsuda et al., 1999). In the past, BHT and butylated hydroxyanisole (BHA) as synthetic antioxidants had been widely used (Branen, 1975). However, many studies were carried out to screen more effective and safer antioxidant from natural sources. The black, red and yellow pigments in soybean are attributed to the accumulation of anthocyanin. Anthocyanins are polyphenols responsible for many of the fruit and floral colors, basic skeleton of which is 2-phenylbenzopyrylium or flavylium glycoside. Anthocyanins are especially abundant in the epidermis palisade layer of the black soybean seed (Yoshida et al., 1996). Three main anthocyanins, i. e., C3G (cyaniding-3-glucoside), D3G (delphinidin-3-glucoside) and 
P3G (petunidin-3-glucoside), were characterized in black soybean seed coat (Tsuda, 1999; Kim et al., 2008). The multi-drug resistance (MDR) is characterized by the cross resistance to broad range of the major obstacles to successful cancer chemotheraphy. A primary mechanism of MDR is attributed to the overexpression of P-glycoprotein (P-gp) in plasma membrane of resistant cell where the P-gp acts as an energy dependent efflux pump, reducing intracellular accumulation of anticancer drugs (Ford and Haith, 1990). Thereby MDR phenomenon greatly limits the efficacy of many anticancer drugs originated from natural products such as vinca alkaloids, anthracycliens and many antitumor antibiotics and this problem may be extended to newly developed taxol and campthotecin. Many kinds of drugs such as calcium channel blockers, calmodulin inhibitors and indole alkaloids are known to reverse MDR by competing with anticancer drugs for binding to P-gp (Ford and Haith, 1990).

The objective of this study, therefore, was to determine antioxidant and multi-drug resistance reversing activities in colored soybean cultivars. The pigmentation of soybean colors could be due to anthocyanin synthesis. The study was designed by the idea that antioxidant activity by TBARS, DPPH, and ABTS methods and multi-drug resistance reversing activity could exhibit differently depending on soybean cultivars with different colors.

\section{Materials and Methods}

\section{Plant materials}

Soybean cultivars with black and brown seed coats were planted at the experimental field of Jeonnam Agricultural Research \& Extension Services in May 2004. The cultivars are "Black \# 1" (black), "Black \# 3" (black), "Jeonnam \# 1" (black), and "Jinyul" (brown). The seeds were harvested at maturity stage, air-dried, and stored at $4{ }^{\circ} \mathrm{C}$ until used. The seeds were three times extracted with $95 \%$ methanol in a shaker at 24-h interval for 3 days at room temperature. Then the extracts were filtered through a Whatman No. 1 filter paper. The collected filtrate was evaporated to dryness under vacuum at $40^{\circ} \mathrm{C}$ using a rotary evaporator $(\mathrm{N}-1000 \mathrm{~V}-\mathrm{W}$, Eyela, Japan). After evaporation, the yield of dried methanol extract was about $10 \%$ of the original plant sample.

\section{TBARS method}

Antioxidant activity for the dried samples was investigated by TBA method. The dried samples of $0.1 \mathrm{~g}$ were homogenized with $10 \mathrm{~g}$ pork meat and then stored at refrigerator at $2^{\circ} \mathrm{C}$. At $168 \mathrm{hr}$ after storage, the mixed samples were added with $25 \mathrm{~mL}$ of $20 \%$ trichloroacetic acid (TCA), homogenized at $14,000 \mathrm{rpm}$ for $2 \mathrm{~min}$, and diluted with distilled water to give final volume into $100 \mathrm{~mL}$. The diluted solution was filtered with Whatman No.1 filter paper. The $5 \mathrm{~mL}$-filtered solution was mixed with $5 \mathrm{~mL}$ TBA $(5 \mathrm{mM})$ and transferred into test tube. The test tube was placed into dark room for $15 \mathrm{hr}$ at $25^{\circ} \mathrm{C}$. Then the solution was measured at the absorbance of $550 \mathrm{~nm}$ through UV-Vis spectrophotometer (Shimadzu UV1650PC, Japan). To evaluate long-term antioxidant activity of plant extracts in meat, TBA-reactive substance (TBARS) values of methanol extracts from the sample were measured at 7 days interval over 14 days, compared with a synthetic antioxidant, BHT $1 \%$. TBARS value test was used to determine the degree of lipid oxidation according to the method of Witte et al. (1970). The values were calculated as follows; TBA $(\mathrm{MA} \mathrm{mg} / 1000 \mathrm{~g})=$ absorbance $* 5.2$. All measurements were replicated with 3 times.

\section{DPPH radical-scavenging activity}

Free radical scavenging activity of the methanol extracts was determined using the classical 1, 1-diphenyl-2-picrylhydrazyl method (DPPH) (Blosi, 1958). Each methanol extract at various concentrations $(250,500,1000,2500$, and $5000 \mathrm{ppm})$ was added to a $1.5 \times 10^{-4} \mathrm{M}$ solution of DPPH in methanol and the reaction mixture was shaken vigorously. The amount of DPPH remaining was determined at $520 \mathrm{~nm}$, and the radical scavenging activity was obtained from the following equation:

$$
\begin{aligned}
& \text { Radical scavenging activity }(\%) \\
& =\left\{\left(\mathrm{OD}_{\text {control }}-\mathrm{OD}_{\text {sample }}\right) / \mathrm{OD}_{\text {control }}\right\} \times 100 .
\end{aligned}
$$

\section{ABTS Assay}

$\mathrm{ABTS}^{+}$radical cation method (Miller et al., 1993) was modified to evaluate the free radical scavenging effect of Korean colored soybean extracts (Pellegrini et al., 1999). The ABTS reagent was prepared by mixing $5 \mathrm{~mL}$ of $7 \mathrm{mM}$ ABTS with $2.45 \mathrm{mM}$ potassium persulfate. After the mixture was 
kept in the dark at room temperature for $15 \mathrm{~h}$ to allow for the completion of radical generation, it was diluted with ethanol $(1: 44, \mathrm{v} / \mathrm{v})$. To determine the scavenging activity, $3 \mathrm{~mL}$ of ABTS reagent was mixed with $150 \mu \mathrm{L}$ of samples in a 96-well microplate and incubated at room temperature for 5 min. After incubation, the absorbance was measured at 734 nm using a microplate reader, and $75 \%$ ethanol was used as a control. The $\mathrm{ABTS}^{+}$scavenging effect was calculated as;

$$
\left[\left(\mathrm{OD}_{734 \text { control}}-\mathrm{OD}_{734 \text { sample }}\right) /\left(\mathrm{OD}_{734 \text { control }}\right)\right] \times 100 \% \text {. }
$$

\section{Multi-drug resistance reversing activity}

The cytotoxicity of each compound was determined in KB-V1 cells in the absence or presence of $100 \mathrm{nM}$ of VLB by method of Ford and Haith (1990). VLB cytotoxicity enhancement by each compound was expressed as enhancement factor (EF) as following;

$$
\begin{aligned}
\mathrm{EF}= & \mathrm{IC}_{50} \text { of modulator on } \mathrm{KB}-\mathrm{V} 1 \text { cells without } \mathrm{VLB} / \mathrm{IC}_{50} \\
& \text { of modulator on KB-V1 cells with VLB }
\end{aligned}
$$

In another set of experiment, the effects of compounds on MDR were studied by exposing cells to a range of concentrations of anticancer drugs, ADR, VLB, COL and TX in the absence or presence of MDR reversing compounds. Drug resistance of MDR cells to various anticancer drugs and MDR reversing effect of each compound were expressed as relative resistance (RR) as following;

$$
\begin{aligned}
\mathrm{RR}= & \mathrm{IC}_{50} \text { of anticancer drug with MDR modulator/ } \mathrm{IC}_{50} \text { of } \\
& \text { anticancer drug on sensitive parent cells }
\end{aligned}
$$

\section{Data analysis}

Statistical analysis was performed using Statistical Analysis System procedures (SAS Institute Inc., Cary, NC). When means were significant using the F-test, the means were separated by a least significant difference (LSD) test.

\section{Results and Discussion}

\section{TBARS value}

Antioxidant activity of soybean powder was measured by

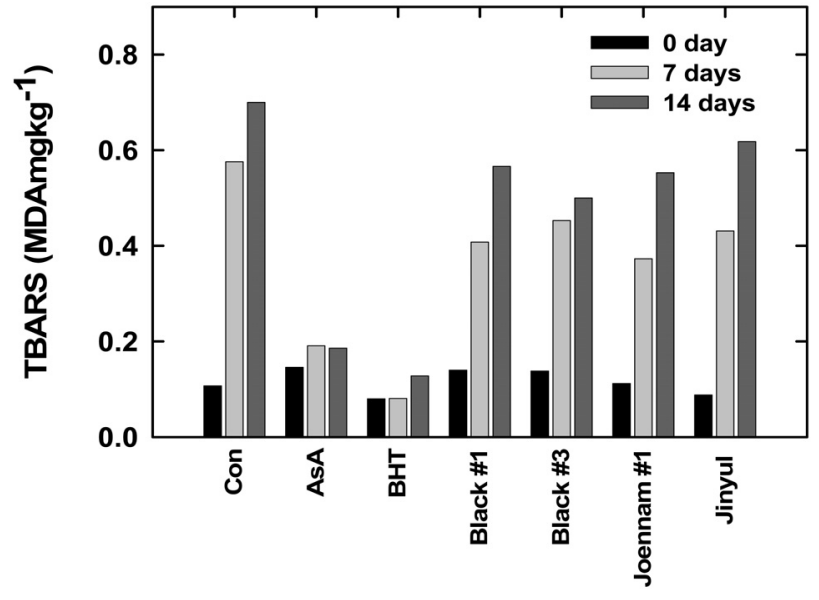

\section{Soybean cultivar}

Fig. 1. Changes in TBARS values of meat treated with colored soybean extracts at different storage periods. Each bar is mean \pm S.E. from three independent experiments. Con: untreated control, AsA: ascorbic acid, and BHT: butylated hydroxytoluene.

TBARS method. The TBARS value was used to determine the degree of lipid oxidation. The highest TBARS values at 0 day were obtained from "Jinyul" cultivar, and followed by, "Jeonnam \#1", "Black \#3"and "Black \#1". At 7 days, however, cultivar "Jeonnam \#1" exhibited strongest antioxidant activity, showing the lowest TBARS value. No siginificant difference in antioxidant activity among cultivars was maintained for 14 days, and the activity was much less than that of synthetic antioxidant BHT or ascorbic acid. TBARS values were different depending on soybean cultivars (Fig. 1).

\section{DPPH radical scavenging activity}

The Table 1 summarized the results of the determination of DPPH radical scavenging activity of methanol extracts from 4 cultivars. As can be seen, cultivar "Jeonnam \#1" showed the highest activity. Methanol extracts at 5,000 ppm from cultivar "Jeonnam \#1" and "Black \#1" showed 74.05 and 69.89\% DPPH radical scavenging activity, showing higher activity than "Black \#1" and "Jinyul" 56.90 and $39.06 \%$, respectively (Table 1). All samples of cultivars showed DPPH radical scavenging activity in a dose-dependent manner. The results are consistent with the finding of TBARS method that the cultivars showed higher antioxidant activity against lipid oxidation. Further studies are required, in progress, to determine 
Table 1. DPPH radical scavenging activity of methanol extracts from Korean colored soybean cultivars.

\begin{tabular}{lccccc}
\hline \hline \multirow{2}{*}{ Cultivars } & \multicolumn{5}{c}{ Extract concentration, ppm } \\
\cline { 2 - 6 } & 250 & 500 & 1,000 & 2,500 & 5,000 \\
\hline Black \#1 & $15.41 \pm 2.17 \mathrm{ab}$ & $19.67 \pm 2.05 \mathrm{~b}$ & $38.55 \pm 3.05 \mathrm{a}$ & $61.07 \pm 4.16 \mathrm{ab}$ & $69.89 \pm 5.19 \mathrm{a}$ \\
Black \#3 & $12.54 \pm 1.05 \mathrm{bc}$ & $20.14 \pm 2.23 \mathrm{~b}$ & $26.80 \pm 3.15 \mathrm{~b}$ & $46.75 \pm 3.52 \mathrm{bc}$ & $56.90 \pm 5.28 \mathrm{ab}$ \\
Jeonnam \#1 & $19.77 \pm 2.12 \mathrm{a}$ & $33.74 \pm 2.92 \mathrm{a}$ & $47.53 \pm 2.87 \mathrm{a}$ & $69.47 \pm 5.86 \mathrm{a}$ & $74.05 \pm 7.56 \mathrm{a}$ \\
Jinyul & $7.64 \pm 0.92 \mathrm{c}$ & $8.93 \pm 1.33 \mathrm{c}$ & $14.90 \pm 1.26 \mathrm{c}$ & $34.98 \pm 4.07 \mathrm{c}$ & $39.06 \pm 5.05 \mathrm{~b}$ \\
\hline
\end{tabular}

${ }^{\mathrm{z}}$ Data represent the mean values $\pm \mathrm{SE}$ of three independent experiments. Different small letter within the columns means significant differences among soybean cultivars $(p<0.05)$.

Table 2. Relative scavenging activity of ABTS + free radical of methanol extracts from Korean colored soybean cultivars.

\begin{tabular}{lccccc}
\hline \hline \multirow{2}{*}{ Cultivars } & \multicolumn{5}{c}{ Extract concentration, ppm } \\
\cline { 2 - 6 } & 250 & 500 & 1,000 & 2,500 & 5,000 \\
\hline Black \#1 & $16.5 \pm 1.31 \mathrm{~b}$ & $21.1 \pm 0.55 \mathrm{~b}$ & $26.9 \pm 1.27 \mathrm{~b}$ & $39.7 \pm 1.56 \mathrm{~b}$ & $44.6 \pm 2.51 \mathrm{~b}$ \\
Black \#3 & $13.9 \pm 1.15 \mathrm{c}$ & $23.2 \pm 3.22 \mathrm{ab}$ & $17.8 \pm 1.33 \mathrm{c}$ & $28.8 \pm 1.12 \mathrm{c}$ & $36.3 \pm 3.05 \mathrm{c}$ \\
Jeonnam \#1 & $23.6 \pm 1.31 \mathrm{a}$ & $25.2 \pm 1.04 \mathrm{a}$ & $31.7 \pm 2.32 \mathrm{a}$ & $43.5 \pm 2.09 \mathrm{a}$ & $49.4 \pm 2.07 \mathrm{a}$ \\
Jinyul & $6.4 \pm 0.41 \mathrm{~d}$ & $8.8 \pm 1.22 \mathrm{c}$ & $10.6 \pm 0.53 \mathrm{~d}$ & $21.2 \pm 1.10 \mathrm{~d}$ & $27.2 \pm 1.26 \mathrm{~d}$ \\
\hline
\end{tabular}

${ }^{\mathrm{z}}$ Data represent the mean values $\pm \mathrm{SE}$ of three independent experiments. Different small letter within the columns means significant differences among soybean cultivars $(p<0.05)$.

which compounds are responsible for the antioxidant activity. Jung et al. (2008) reported that relatively high correlation between free radical scavenging and total phenolic contents in Ulmus davidiana extracts was observed.

\section{ABTS Assay}

All samples of cultivars showed ABTS radical scavenging activity in a dose-dependent manner. The highest ABTS values were obtained from "Jeonnam \#1" cultivar, and followed by, "Black \#1", "Black \#3", and "Jinyul". Methanol extracts at $5000 \mathrm{mg} \mathrm{kg}^{-1}$ from cultivar "Jeonnam \#1" exhibited strongest antioxidant activity by $49.4 \%$ (Table 2). Also others (Kim et al., 2008; Tsuda et al., 1999) reported that antioxidant activity of anthocyanins $\mathrm{C} 3 \mathrm{G}$ and $\mathrm{D} 3 \mathrm{G}$ from colored soybeans was highly correlated with their content.

\section{Multi-drug resistance reversing activity}

In our search for MDR reversing agents from natural product, methanol extracts from soybean cultivars were screened for multidrug resistance reversing activity using drug sensitive KB-3-1 and multidrug resistance KB-V1 cells. The effects of isolated compounds on the cell growth were determined in both drug sensitive KB-3-1 and MCF7 cells and resistant

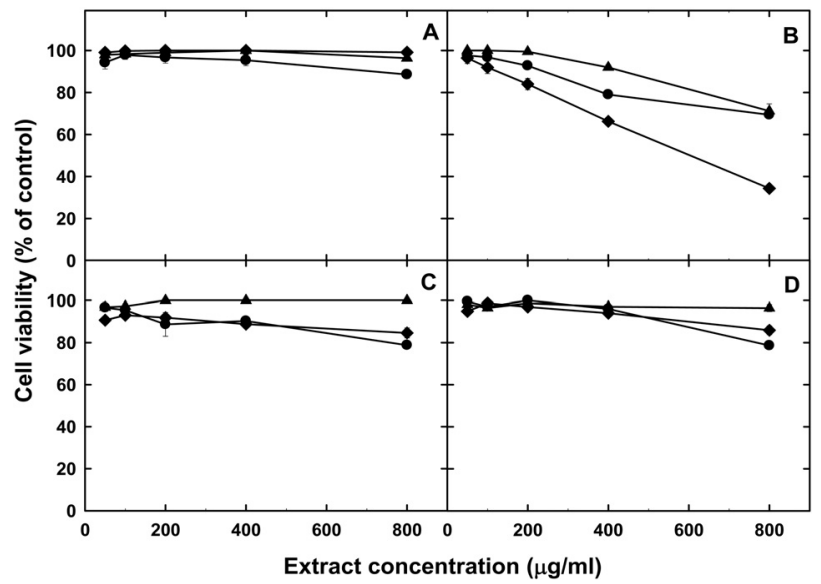

Fig. 2. Daunorubicin and reversal effect of methanol extracts of colored soybean seeds on human acute myelogenous leukemia cell. Date were presented as means $\pm \mathrm{SD}(\mathrm{n}=3)$. - : wild type of human acute myelogenous leukemia, $\checkmark$ : daunorubicin resistant type in the absence of VCR, and $\mathbf{\Delta}-\mathbf{\Lambda}$ : daunorubicin resistant type in the presence of VCR. A: cultivar "Black \# 1", B: cultivar "Black \# 3", C: cultivar "Jeonnam \# 1", D: cultivar "Jinyul".

KB-V1 and MCF7/ADR cells. All the compounds did not show significant cytotoxicity to the cell lines tested. The highest multidrug resistance reversing activity exhibited in "Black \# 3" and followed by "Jinyul", "Jeonnam \# 1" and 
"Black \# 1" (Fig. 2). These results indicate that MDR reversing effects of torilin and wilfoside might be directly associated with the increase of the intracellular accumulation of anticancer drugs by blocking the drug efflux exerted by P-gp (Ford and Haith, 1990). Kim et al. (2008) reported that D3G from Korean black soybean showed higher cytotoxicity than other pigments in Jurkat cancer cell line whereas activity of $\mathrm{C} 3 \mathrm{G}$ was high in MCF-F cancer cell lines.

In conclusion, this study shows that soybean seed color affected antioxidant and multidrug resistance reversing activities. However, the results of TBARS assay were not consistent with those of DPPH radical scavenging activity and multidrug resistance reversing activity. Especially, colored soybean cutivar "Jeonnam \# 1" showed the highest DPPH radical scavenging activity, while "Black \# 3" exhibited the highest multidrug resistance reversing activity. These results suggest that seed colors of soybean may play an important role in antioxidant activity and multidrug resistance reversing activity, and that the activity was different depending on cultivar or its color. The results showed that various compounds such as anthocynins that cause antioxidant activity could be produced with different amount from cultivars. Therefore, it is believed that supplementation of human diets with soybean anthocyanin may reduce human cancer and aging.

\section{Literature Cited}

Blois, M.S. 1958. Antioxidant determinations by use of a stable free radical. Nature 26:1199-1200.

Branen, A.L. 1975. Toxicology and biochemistry of butylated hydroxyanisole and butylated hydroxytoluene. J. American Oil Chem. Soc. 52:59-63.

Darbon, J.M., M. Penary, N. Escalas, F. Casagrande, F. Goubin-Gramatica, C. Baudouini and B. Ducommun. 2000. Distinct $\mathrm{Chk} 2$ activation pathways are triggered by genistein and DNA-damaging agents in human melanoma cells. J. Biol. Chem. 275(20):15363-15369.

Esaki, H., H. Onozaki, S. Kawakishi and T. Osawa. 1997. Antioxidant activity and isolation from soybeans fermented with Aspergillus spp. J. Agric. Food. Chem. 45:2020-2024.

Ford, J.M. and W.N. Haith. 1990. Pharmacology of drugs that alter multidrug resistance in cancer. Pharmacol. Rev. 42:155-199.
Jung, M.J., S.I. Heo and M.H. Wang. 2008. Free radical scavenging and total phenolic contents from methanolic extracts of Ulmus davidiana. Inter. J. Food Sci. Nutr. 108:482-487.

Kim, Y.H., D.S. Kim, S.S. Woo, H.H. Kim, Y.S. Lee, H.S. Kim, K.O. Ko and S.K. Lee. 2008. Antioxidant activity and cytotoxicity on human cancer cells of anthocyanin extracted from black soybean. Korean J. Crop Sci. 53(4): 407-412.

Meiers, S., M. Kemeny, U. Weyand, R. Gastpar, E. von Angerer and D. Marko. 2001. The anthocyanidins cyanidin and delphinidin are potent inhibitors of the epidermal growthfactor receptor. J. Agric. Food Chem. 49:958-962.

Miller, N.J., C.A. Rice-Evans, M.J. Davies, V. Gopinathan and A. Milner. 1993. A novel method for measuring antioxidant capacity and its application to monitoring the antioxidant status in premature neonates. Clinical Sci. 84:407-412.

Ohta, T., S. Ishikura, S. Shintani, N. Usami and A. Hara. 2000. Kinetic alteration of a human dihydrodiol/3a-hydroxysteroid dehydrogenase isoenzyme, AKR1C4, by replacement of histidine-216 with tyrosine or phenylalanine. Biochem. J. 352:685-691.

Pellegrini, N., M. Ying and C. Rice-Evans. 1999. Screening of dietary carotenoids and carotenoid-rich fruits extract for antioxidant activities applying 2,2-azobis (3-ethylbenzothine6-surfonic acid) radical cation decolorization assay. Method. Enzymol. 299:384-389.

Tsuda T., F. Horio, J. Kitoh and T. Osawa.1999. Protective effects of dietary cyaniding-3-O-beta-glucoside on liver Ischemia-referfusion injury in rats. Archives. Biochem. Biophys. 368(2):361-366.

Wei, H., R. Brown, Q. Cai, S. Barnes and Y. Wang. 1995. Antioxidant and antipromotional effects of the soybean isoflavone genistein. Proc. Soc. Exp. Biol. Med. 280(1): 124-130.

Witte, V.C., G.F. Krause and M.E. Bailey. 1970. A new extraction method for determining 2-thiobarbituric acid values of pork and beef during storage. J. Food Sci. 35:582-587.

Yoshida, K., Y. Sato, R. Okuno, K. Kameda, M. Isobe and Y. Kondo. 1996. Structural analysis and measurement of anthocyanin from colored seed coats of Vigna, Phaseous, and Glycine legumes. Biosci. Biotechnol. Biochem. 60:589-593.

(Received 17 May 2011 ; Accepted 18 June 2011) 